Research Paper

\title{
Treatment outcomes regarding the addition of targeted agents in the therapeutic portfolio for stage II-III rectal cancer undergoing neoadjuvant chemoradiation
}

\author{
Jin-Tung Liang ${ }^{1}$, Tzu-Chun Chen ${ }^{1}$, John Huang ${ }^{1}$, Yung-Ming Jeng ${ }^{2}$ and Jason Chia- \\ Hsien Cheng ${ }^{3}$ \\ ${ }^{1}$ Division of Colorectal Surgery, National Taiwan University Hospital and College of Medicine, Taipei, Taiwan \\ ${ }^{2}$ Department of Pathology, National Taiwan University Hospital and College of Medicine, Taipei, Taiwan \\ ${ }^{3}$ Department of Radiation Oncology, National Taiwan University Hospital and College of Medicine, Taipei, Taiwan \\ Correspondence to: Jin-Tung Liang, email: jintung@ntu.edu.tw \\ Keywords: bevacizumab; cetuximab; CCRT; rectal cancer; total mesorectal excision \\ Abbreviations: CCRT: Concurrent chemoradiation therapy; FOLFOX: folinic acid + leucovorin + oxaliplatin; TME: Total mesorectal excision \\ Received: April 13, $2017 \quad$ Accepted: August 29, $2017 \quad$ Published: October 10, 2017 \\ Copyright: Liang et al. This is an open-access article distributed under the terms of the Creative Commons Attribution License 3.0 \\ (CC BY 3.0), which permits unrestricted use, distribution, and reproduction in any medium, provided the original author and source \\ are credited.
}

\section{ABSTRACT}

Background: To evaluate the impact of targeted agents in stage II-III rectal cancer undergoing neoadjuvant concurrent chemoradiation therapy (CCRT).

Method: A retrospective study was performed in 124 consecutive patients with clinically $\mathbf{T}_{3} \mathbf{N}_{0-2} \mathrm{M}_{0}$-staged rectal cancer incorporating targeted agents in CCRT.

Results: Pathologic complete response was detected in $34.2 \%(n=26)$ of bevacizumab+FOLFOX-treated patients $(n=76)$, which was significantly higher $(p=0.019$, post-hoc statistical power $=35.87 \%)$ than that $(n=10,20.8 \%)$ of the cetuximab+FOLFOX-treated patients $(n=48)$. Patients receiving cetuximab+FOLFOX therapy tended to develop severe liver toxicity $(91.7 \%, n=44$ versus $17.1 \%, n=13$, p $<0.0001$ ), as evaluated by morphologic grading of hepatic steatosis and sinusoidal dilatation in laparoscopy. In the $\mathbf{5 7}$ patients with morphologically severe liver toxicity, $36(63.2 \%)$ retained a normal liver function; for the remaining 21 patients with an abnormal liver function, the abnormality was self-limited in 19 patients, whereas 2 cetuximab-treated patients progressed to hepatic failure and mortality. A subset analysis within bevacizumab+FOLFOX-treated patients with either wild-type $(n=36)$ or mutant $(n=40) K$-ras status indicated $K$-ras status did not significantly influence the treatment outcomes.

Conclusions: The addition of bevacizumab instead of cetuximab to FOLFOX in the neoadjuvant settings for $T_{3} N_{0-2} M_{0}$-staged rectal cancer could induce a promising rate of pathologic complete response and lesser hepatotoxicity.

\section{INTRODUCTION}

Preoperative concurrent chemoradiation therapy (CCRT) followed by a standardized total mesorectal excision (TME) is emerging as the new treatment paradigm for advanced low rectal cancer [1-2]. It is generally accepted that the pathologic stage, i.e., the response of cancer to CCRT, is the most powerful predictor for the survival of patients with advanced rectal cancer after CCRT [3-6]. To enhance the tumor response to CCRT, the chemotherapeutic agents in the CCRT protocol have been evolving. Before the year 2000, we routinely used the Mayo regimens as chemotherapy protocol in the CCRT setting. However, since 2003, we have widely adopted FOLFOX (oxaliplatin/5fluorouracil/leucovorin) as the chemotherapeutic regimen for patients with stage II or III rectal cancer requiring preoperative CCRT, and such regimen can significantly promote the tumor response as reported elsewhere [7-11]. 
Recently, combining targeted agents (bevacizumab or cetuximab) with chemotherapeutic regimens (XELOX: capecitabine / oxaliplatin, FOLFOX4, and FOLFIRI: 5-fluorouracil / leucovorin / irinotecan), with the high response rate, is increasingly being recognized as state-of-the-art in the neoadjuvant treatment of liver metastasis from colorectal cancer [12-13], although the accompanying liver toxicities such as sinusoidal dilatation and steatosis may paradoxically affect the surgical morbidity of liver resection. Remarkably, since March 2008, the K-ras mutational status of the tumor has been recognized as a biomarker to predict the response to cetuximab therapy [14]. However, the application of cetuximab to the preoperative CCRT regimens has only been sporadically reported to be feasible [15-16]. Therefore, it deserves further investigation whether the safety and efficacy of cetuximab therapy in the neoadjuvant setting of liver metastasis can be extrapolated to that of locally advanced rectal cancer [17], especially in the era in which the K-ras status is reckoned as a useful biomarker.

On the other hand, Willet et al. has provided direct evidence that bevacizumab has antivascular effects in human rectal cancer, and complete pathologic response to bevacizumab and chemoradiation in patients with advanced rectal cancer has been observed thereafter [18-19]. Theoretically, with the unique pharmaceutical features: blockade of angiogenesis, and improvement of the delivery of cytotoxic chemotherapeutic agents to tumor bulk by altering or normalizing the tumor vasculature, bevacizumab may be promising in the clinical context of combination therapy. However, the widespread acceptance of bevacizumab in the neoadjuvant clinical setting is limited by concerns about the bevacizumabrelated surgical complications such as bleeding tendency, delayed wound healing, enterocutaneous fistula, and thromboembolism [20].

In the present study, we made a retrospective study to better clarify the impact regarding the addition of bevacizumab versus cetuximab to FOLFOX as preoperative CCRT regimens in patients with stage II-III rectal cancer.

\section{RESULTS}

\section{Patient accrual and treatment course}

124 patients undergoing the treatment program were recruited, with 76 patients categorized to the bevacizumab+FOLFOX group and the other 48 to the cetuximab+FOLFOX group. All patients completed the entire radiotherapy as prescribed without interruptions. However, only $88.7 \%(\mathrm{n}=110)$ patients complete the whole 6 courses of chemotherapy, with the remaining 14 patients whose chemotherapy were quitted after the second course $(n=3)$, the third course $(n=4)$, the fourth course $(n=2)$, and the fifth course $(n=5)$, respectively.

\section{Clinicopathologic features of patients before and after CCRT}

There was no significant difference between the 2 groups regarding the demographics and various clinicopathologic parameters (Table 1). After CCRT, pathologic complete response (tumor regression grade 5) was detected in $34.2 \%(n=26)$ of patients in the bevacizumab+FOLFOX group, which was significantly higher $(p=0.019)$ than $20.8 \%(n=10)$ in patients in the cetuximab+FOLFOX group (Table 2), with post-hoc statistical power of $35.87 \%$. However, there was no significant difference between the two groups $(75.0 \%$, $\mathrm{n}=57$ in the bevacizumab+FOLFOX group versus $66.7 \%$, $\mathrm{n}=32$, in the cetuximab+FOLFOX group, $\mathrm{p}>0.05$ ), when the patients with tumor regression grade 5 and 4 (residual tumor cells represented less than $10 \%$ in histology) were lumped together and compared.

When the pathologic complete response rate was compared among $\mathrm{T}_{3} \mathrm{~N}_{0}, \mathrm{~T}_{3} \mathrm{~N}_{1}$, and $\mathrm{T}_{3} \mathrm{~N}_{2}$ groups of patients (Table 1), we found that it had been very difficult to achieve a complete remission of cancer in metastasized lymph nodes, because it was only detected in $11.8 \%$ $(n=6 / 51)$ of patients with clinically positive lymph node metastasis.

\section{Adverse effects of CCRT and surgical complications}

There was no difference between the bevacizumab+FOLFOX and cetuximab+FOLFOX group of patients in regard to CCRT-related severe adverse events $(9.2 \%, \mathrm{n}=7$ versus $8.3 \%, \mathrm{n}=4$, Table 3$)$, and surgeryrelated morbidity $(13.2 \%, \mathrm{n}=9$ versus $8.3 \%, \mathrm{n}=4)$ or mortality $(1.3 \%, \mathrm{n}=1$ versus $4.2 \%, \mathrm{n}=2$, Table 4$)$. However, compared with the bevacizumab+FOLFOX therapy, the cetuximab+FOLFOX therapy tended to have less blood loss during surgery (Table 3) but was associated with more severe liver toxicity $(91.7 \%, n=44$ versus $17.1 \%$, $\mathrm{n}=13, \mathrm{p}<0.0001$ ) (Table 5). Remarkably, 36 (63.2\%) of the patients with morphologically severe liver toxicity $(n=57)$ remained a normal liver function, as evaluated by serum level of alanine aminotransferase (ALT) after CCRT (Figure 1). Even for the 21 patients with abnormal liver function (ALT level: median: $94 \mathrm{U} / \mathrm{L}$, range: 54-244 U/L, $\mathrm{n}=21$ ), the abnormality was self-limited and recovered within 3 months after surgery in most patients $(90.4 \%, n=19)$ However, 2 cetuximab-treated patients did progress to hepatic failure and mortality after surgery. The cause of death in these 2 patients was ascribed to hepatic failure because their preoperative function was normal and ultimately developed an impairment of liver function meeting the Child $\mathrm{C}$ criteria. 
Table 1: Demographics and disease characteristics

\begin{tabular}{|c|c|c|c|c|}
\hline \multirow{3}{*}{ Characteristics } & \multicolumn{2}{|c|}{$\begin{array}{l}\text { Bevacizumab+ } \\
\text { FOLFOX K-ras }\end{array}$} & \multirow{2}{*}{$\begin{array}{c}\begin{array}{c}\text { Cetuximab+ } \\
\text { FOLFOX K-ras }\end{array} \\
\text { wild-type }\end{array}$} & \multirow[t]{2}{*}{ P-value } \\
\hline & mutant & wild-type & & \\
\hline & $(n=40)$ & $(n=36)$ & $(n=48)$ & \\
\hline \multicolumn{5}{|l|}{ Age (year) } \\
\hline Median & 57 & 58 & 59 & \multirow{2}{*}{ NS } \\
\hline Range & $28-75$ & $34-75$ & $30-75$ & \\
\hline \multicolumn{5}{|l|}{ Gender } \\
\hline Male & 24 & 20 & 26 & \multirow{2}{*}{ NS } \\
\hline Female & 16 & 16 & 22 & \\
\hline \multicolumn{5}{|c|}{$\begin{array}{l}\text { Clinical staging (Pre- } \\
\text { CCRT) }\end{array}$} \\
\hline T3N0 & 24 & 20 & 29 & \multirow{3}{*}{ NS } \\
\hline $\mathrm{T} 3 \mathrm{~N} 1$ & 10 & 9 & 14 & \\
\hline T3N2 & 6 & 7 & 5 & \\
\hline \multicolumn{5}{|l|}{ Differentiation } \\
\hline Well & 6 & 5 & 6 & \multirow{3}{*}{ NS } \\
\hline Moderate & 32 & 28 & 38 & \\
\hline Poor & 2 & 3 & 4 & \\
\hline \multicolumn{5}{|c|}{ Mucin production } \\
\hline+ & 6 & 7 & 7 & \multirow{2}{*}{ NS } \\
\hline- & 34 & 29 & 41 & \\
\hline \multicolumn{5}{|c|}{$\begin{array}{l}\text { L/N metastasis (post- } \\
\text { CCRT) }\end{array}$} \\
\hline+ & 15 & 16 & 20 & \multirow{2}{*}{ NS } \\
\hline- & 25 & 20 & 28 & \\
\hline \multicolumn{5}{|c|}{$\begin{array}{l}\text { Lymphatic/vascular } \\
\text { invasion (post- } \\
\text { CCRT) }\end{array}$} \\
\hline+ & 14 & 15 & 17 & \multirow{2}{*}{ NS } \\
\hline- & 26 & 21 & 31 & \\
\hline \multicolumn{5}{|l|}{$\begin{array}{l}\text { Harvested L/N } \\
\text { number }\end{array}$} \\
\hline median & 10 & 11 & 9 & \multirow{2}{*}{ NS } \\
\hline range & $4-28$ & $6-24$ & $5-22$ & \\
\hline \multicolumn{5}{|l|}{ CRM } \\
\hline+ & 1 & 1 & 2 & \multirow{2}{*}{ NS } \\
\hline- & 39 & 35 & 46 & \\
\hline
\end{tabular}

Abbreviation: CRM: circumferential resection margin; L/N: lymph node; NS: not statistically significant. 
Table 2: Histopathologic features of the primary colorectal cancer in response to CCRT

\begin{tabular}{|c|c|c|c|c|c|}
\hline \multirow{3}{*}{ Characteristics } & \multicolumn{2}{|c|}{ Bevacizumab+FOLFOX K-ras } & \multirow[t]{2}{*}{ total } & \multirow{2}{*}{$\frac{\text { Cetuximab+FOLFOX K-ras }}{\text { wild-type }}$} & \multirow[t]{2}{*}{ P-value } \\
\hline & mutant & wild-type & & & \\
\hline & $(n=40)$ & $(n=36)$ & & $(n=48)$ & \\
\hline \multicolumn{6}{|l|}{ Pathologic response } \\
\hline $\begin{array}{l}\text { Grade } 0: \text { no regression } \\
\text { distant metastasis } \\
\text { (progressive disease) }\end{array}$ & 1 & 1 & 2 & 2 & \\
\hline $\begin{array}{l}\text { Grade 1: dominant } \\
\text { tumor mass }(>50 \%) \\
\text { with obvious fibrosis (no } \\
\text { response) }\end{array}$ & 3 & 4 & 7 & 4 & \\
\hline $\begin{array}{l}\text { Grade 2: obvious tumor } \\
\text { cells }(25-50 \%) \text { with } \\
\text { dominant fibrosis (stable } \\
\text { disease) }\end{array}$ & 2 & 3 & 5 & 6 & \\
\hline $\begin{array}{l}\text { Grade } 3 \text { : few tumor cells } \\
(10-25 \%) \text { with dominant } \\
\text { fibrosis (partial response) }\end{array}$ & 3 & 2 & 5 & 4 & \\
\hline $\begin{array}{l}\text { Grade } 4 \text { : very few tumor } \\
\text { cells }(<10 \%) \text { in fibrotic } \\
\text { tissue (partial response) }\end{array}$ & 17 & 14 & 31 & 22 & \\
\hline $\begin{array}{l}\text { Grade } 5 \text { : no tumor cells, } \\
\text { only fibrotic mass or } \\
\text { acelluar mucin pool } \\
\text { (complete response) }\end{array}$ & 14 & 12 & $\begin{array}{c}26 \\
(34.2 \%)\end{array}$ & $10(20.8 \%)$ & $\mathrm{P}=0.019$ \\
\hline \multicolumn{6}{|l|}{$\begin{array}{l}\text { Concomitant histologic } \\
\text { changes }\end{array}$} \\
\hline Vessel intima fibrosis & 28 & & & 36 & NS \\
\hline Foreign body reaction & 16 & & & 20 & NS \\
\hline Mucin pooling & 24 & & & 25 & NS \\
\hline $\begin{array}{l}\text { Calcification / cholesterol } \\
\text { cleft }\end{array}$ & 15 & & & 22 & NS \\
\hline $\begin{array}{l}\text { Ulceration with mucosa } \\
\text { regeneration }\end{array}$ & 32 & & & 40 & NS \\
\hline
\end{tabular}

*The p-value was calculated based on the comparison between total case number of bevacizumab-treated and cetuximabtreated patients

\section{Survival benefits}

Kaplan-Meier analysis of long-term disease-free survival (follow-up time: median: 82 months, range: 63-94 months) and recurrence pattern shows that the oncologic efficacy of bevacizumab-treated patients was better than that of cetuximab-treated patients $(\mathrm{p}=0.0207)$ (Figure 2-A, Table 6). A subset analysis within bevacizumab-treated patients indicated that the k-ras status was not associated with any clinicopathologic features (Table 1) and treatment outcomes (Table 2-5), as was shown $(\mathrm{p}=0.857)$ in diseasefree survival (Figure 2-B).

\section{DISCUSSION}

The present retrospective study has shown that bevacizumab+FOLFOX can achieve a pathologic complete response rate of clinical stage II-III rectal cancer of up to $34.2 \%$, which is much higher than that of any other contemporary reported case series [8-11, 28]. Remarkably, 
Table 3: Adverse effects in patients with rectal cancer undergoing CCRT

\begin{tabular}{|c|c|c|c|c|c|}
\hline \multirow{3}{*}{ Characteristics } & \multicolumn{2}{|c|}{ Bevacizumab+FOLFOX K-ras } & \multirow[t]{2}{*}{ total } & \multirow{2}{*}{$\frac{\text { Cetuximab+FOLFOX K-ras }}{\text { wild-type }}$} & \multirow[t]{2}{*}{ P-value } \\
\hline & mutant & wild-type & & & \\
\hline & $(n=40)$ & $(n=36)$ & & $(n=48)$ & \\
\hline \multicolumn{6}{|l|}{$\begin{array}{l}\text { FOLFOX-related } \\
\text { toxicity }\end{array}$} \\
\hline Neutropenic fever & 1 & 1 & 2 & 2 & NS \\
\hline Severe diarrhea & 0 & 0 & 0 & 1 & NS \\
\hline \multicolumn{6}{|l|}{ Neuropathy } \\
\hline Grade 1 & 19 & 14 & 33 & 14 & NS \\
\hline Grade 2 & 21 & 22 & 43 & 26 & NS \\
\hline \multicolumn{5}{|c|}{ Bevacizumab-spcific adverse effects } & $\mathrm{P}<0.001$ \\
\hline UGI Bleeding & 2 & 1 & 3 & 1 & \\
\hline Hypertension & 2 & 3 & 5 & 1 & \\
\hline Proteinuria & 1 & 1 & 2 & 1 & \\
\hline $\begin{array}{l}\text { Arterial / venous } \\
\text { thromboembolic events }\end{array}$ & 1 & 1 & 2 & 0 & \\
\hline $\begin{array}{l}\text { Wound-healing } \\
\text { complications }\end{array}$ & 2 & 1 & 3 & 1 & \\
\hline $\begin{array}{l}\text { Gastrointestinal } \\
\text { perforation }\end{array}$ & 1 & 1 & 2 & 0 & \\
\hline Cetuximab-related adv & se effects & & & & $\mathrm{P}<0.001$ \\
\hline \multicolumn{6}{|l|}{ Acne/ Acneiform rash } \\
\hline Grade 1 & 3 & 2 & 5 & 20 & \\
\hline Grade 2 & 1 & 1 & 2 & 28 & \\
\hline \multicolumn{6}{|c|}{ Hand-foot skin reaction (Paronychia) } \\
\hline Grade 1 & 1 & 2 & 3 & 30 & \\
\hline Grade 2 & 2 & 2 & 4 & 18 & \\
\hline $\begin{array}{l}\text { Discontinuations due } \\
\text { to a severe adverse } \\
\text { event (neutropenic }\end{array}$ & & & & & \\
\hline $\begin{array}{l}\text { fever, severe diarrhea, } \\
\text { UGI bleeding, } \\
\text { GI perforation, } \\
\text { thromboembolism) }\end{array}$ & 5 & 2 & 7 & 4 & NS \\
\hline
\end{tabular}

Abbreviation: UGI: upper gastrointestinal tract;

*The p-value was calculated based on the comparison between total case number of bevacizumab-treated and cetuximabtreated patients

when combined with radiotherapy, both oxaliplatin and irinotecan have been reported to be promising. Irinotecan (a topoisomerase I inhibitor) and oxalipaltin (causing intrastand cross-links in DNA,) are DNA damaging agents, and theoretically both of them can be effective as a radiosensitizer. However, the Taiwan National Insurance
Bureau only approves FOLOFOX regimen in the adjuvant setting of stage III rectal cancer, based on the evidence from Mosaic clinical trial [7], in which FOLFOX was beneficial in the adjuvant setting of stage III colon cancer. Moreover, we are concerned about the adverse effect of severe diarrhea superimposed by irinotecan on radiotherapy. Therefore, in 
Table 4: Surgical complications in patients with rectal cancer after CCRT

\begin{tabular}{|c|c|c|c|c|c|}
\hline \multirow{3}{*}{ Characteristics } & \multicolumn{2}{|c|}{ Bevacizumab+FOLFOX K-ras } & \multirow[t]{2}{*}{ total } & \multirow{2}{*}{$\frac{\text { Cetuximab+FOLFOX K-ras }}{\text { wild-type }}$} & \multirow[t]{2}{*}{ P-value* } \\
\hline & mutant & wild-type & & & \\
\hline & $(n=40)$ & $(n=36)$ & & $(n=48)$ & \\
\hline \multicolumn{6}{|l|}{ ASA grade } \\
\hline I & 21 & 14 & & 26 & \\
\hline II & 17 & 20 & & 19 & $\mathrm{P}<0.0001$ \\
\hline III & 2 & 2 & & 3 & \\
\hline \multicolumn{6}{|l|}{ Types of operation } \\
\hline APR & 4 & 4 & & 5 & NS \\
\hline LAR & 31 & 28 & & 39 & \\
\hline Pull-through & 5 & 4 & & 4 & \\
\hline \multicolumn{6}{|l|}{ Surgical morbidity } \\
\hline $\begin{array}{l}\text { Blood loss (ml, } \\
\text { median/range) }\end{array}$ & $340(100-800)$ & $\begin{array}{c}350 \\
(100-1000)\end{array}$ & $\begin{array}{c}450 \\
(100- \\
1000)\end{array}$ & $\begin{array}{c}130 \\
(40-600)\end{array}$ & $\mathrm{P}<0.0001$ \\
\hline $\begin{array}{l}\text { Deep vein } \\
\text { thrombosis }\end{array}$ & 1 & 1 & 2 & 1 & \\
\hline Pelvic abscess & 1 & 1 & 2 & 1 & \\
\hline $\begin{array}{l}\text { Enterocutaneous } \\
\text { fistula }\end{array}$ & 1 & 1 & 2 & 1 & \\
\hline Perineal fistula & 1 & 0 & 1 & 1 & \\
\hline $\begin{array}{l}\text { Rectovaginal } \\
\text { fistula }\end{array}$ & 1 & 1 & 2 & 0 & \\
\hline \multicolumn{6}{|l|}{ Surgical mortality } \\
\hline Hepatic failure & 0 & 0 & 0 & 2 & \\
\hline AMI & 1 & 0 & 1 & 0 & \\
\hline
\end{tabular}

* Abbreviation: APR: abdominoperineal resection; LAR: low anterior resection; Pull-through: abdominoanal pull-through procedure with coloanal anastomosis; "ASA: American society of anesthesiology; NS: not statistically significant; AMI: acute myocardial infarction

*The p-value was calculated based on the comparison between total case number of bevacizumab-treated and cetuximabtreated patients

this study, only an oxaliplatin-based regimen was devised and implemented. Previous reports have indicated that FOLFOX regimen can induce the complete response rate of rectal cancer to CCRT of up to $25 \%$ [7-11]. We speculated that the even higher complete response rate in the present series was attributed to the synergistic effect of bevacizumab to the FOLFOX regimen. Simultaneously, the present study again indicated that the surgical complications inherent to the use of bevacizumab such as bleeding tendency, thromboembolism, and enterocutaneous fistula did occur, but their incidence was low provided that the surgical intervention was postponed to 4-6 weeks after the final dose of bevacizumab therapy.
There have been ample evidences to prove that a higher complete response rate of rectal cancer to CCRT can translate into better local control and improved survival of patients [3-6]. In the present case series, only $2(7.7 \%)$ of the 26 patients with complete response to bevacizumab+FOLOFOX therapy developed distant metastasis, in contrast to $11(22.0 \%)$ patients who developed distant metastasis with or without simultaneous local recurrence in the remaining 50 patients without complete response (Table 2,6). Therefore, we think that the encouraging oncologic complete response rate of advanced rectal cancer to bevacizumab+FOLFOX regimens in the 
Table 5: The concomitant liver toxicity in response to CCRT for rectal caner

\begin{tabular}{|c|c|c|c|c|c|}
\hline \multirow{3}{*}{ Characteristics } & \multicolumn{2}{|c|}{ Bevacizumab+FOLFOX K-ras } & \multirow[t]{2}{*}{ total } & \multirow{2}{*}{$\frac{\text { Cetuximab+FOLFOX K-ras }}{\text { wild-type }}$} & \multirow[t]{2}{*}{ P-value ${ }^{*}$} \\
\hline & mutant & wild-type & & & \\
\hline & $(n=40)$ & $(n=36)$ & & $(n=48)$ & \\
\hline \multicolumn{6}{|l|}{ Liver toxicity } \\
\hline \multicolumn{6}{|l|}{ Overall } \\
\hline Severe & 8 & 5 & $13(17.1 \%)$ & $44(91.7 \%)$ & $\mathrm{P}<0.0001$ \\
\hline Moderate & 20 & 17 & & 4 & \\
\hline Mild & 12 & 14 & & 0 & \\
\hline \multicolumn{6}{|c|}{$\begin{array}{l}\text { Sinusoidal dilatation } \\
\text { (blue liver) }\end{array}$} \\
\hline Severe & 6 & 3 & & 25 & \\
\hline Moderate & 14 & 13 & & 23 & \\
\hline Mild / absent & 20 & 20 & & 0 & \\
\hline \multicolumn{6}{|c|}{$\begin{array}{l}\text { Liver steatosis (yellow } \\
\text { liver) }\end{array}$} \\
\hline Severe & 2 & 2 & & 5 & \\
\hline Moderate & 14 & 11 & & 30 & \\
\hline Mild / absent & 24 & 23 & & 13 & \\
\hline
\end{tabular}

*The p-value was calculated based on the comparison between total case number of bevacizumab-treated and cetuximabtreated patients

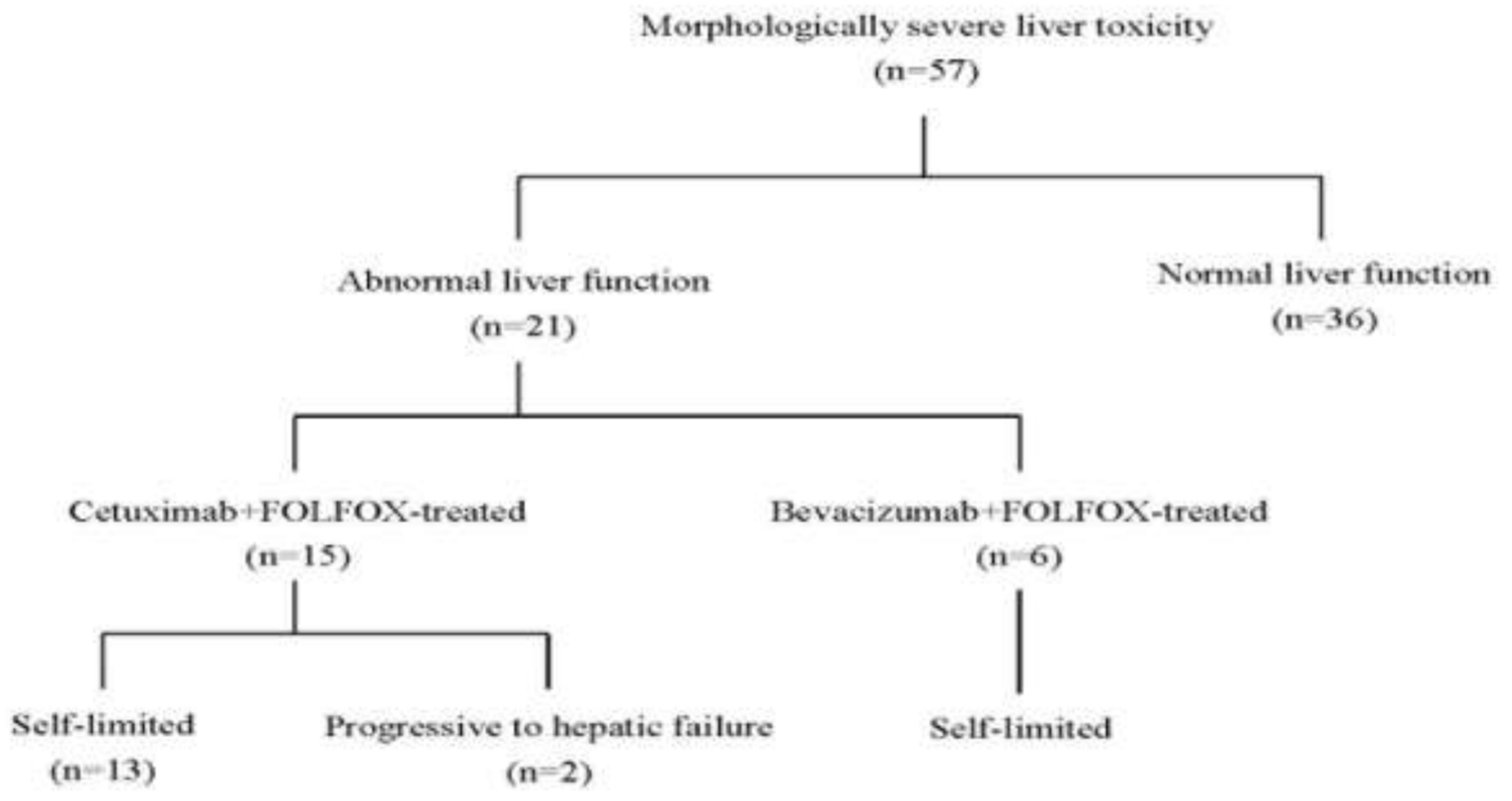

Figure 1: Profile of liver injury in patients receiving preoperative CCRT. 
Table 6: Comparison of recurrence patterns between bevacizumab+FOLFOX $(n=76)$ and cetuximab+FOLFOX $(n=48)$ treated patients

\begin{tabular}{|c|c|c|c|c|c|}
\hline \multirow{3}{*}{ recurrence patterns } & \multicolumn{2}{|c|}{ Bevacizumab+FOLFOX K-ras } & \multirow[t]{2}{*}{ total } & \multirow{2}{*}{$\frac{\text { Cetuximab+FOLFOX K-ras }}{\text { wild-type }}$} & \multirow[t]{2}{*}{ P-value } \\
\hline & mutant & wild-type & & & \\
\hline & $(n=40)$ & $(n=36)$ & & $(n=48)$ & \\
\hline \multicolumn{6}{|l|}{ Distant metastasis } \\
\hline Liver & 1 & 1 & 2 & 0 & \\
\hline Lung & 0 & 1 & 1 & 1 & \\
\hline Bone & 0 & 0 & 0 & 1 & \\
\hline $\begin{array}{l}\text { Para-aortic lymph } \\
\text { nodes }\end{array}$ & 1 & 0 & 1 & 0 & \\
\hline $\begin{array}{c}\text { Peritoneal } \\
\text { carcinomatosis }\end{array}$ & 0 & 1 & 1 & 0 & \\
\hline \multicolumn{6}{|l|}{$\begin{array}{l}\text { Multiple organ } \\
\text { metastases }\end{array}$} \\
\hline Liver + Lung & 1 & 1 & 2 & 1 & \\
\hline Liver + Bone & 0 & 0 & 0 & 1 & \\
\hline \multicolumn{6}{|l|}{ Local recurrence } \\
\hline Presacrum & 0 & 1 & 1 & 1 & \\
\hline Pelvic side wall & 1 & 0 & 1 & 1 & \\
\hline \multicolumn{6}{|l|}{ Distant metastasis plus } \\
\hline \multicolumn{6}{|l|}{ Local recurrence } \\
\hline Lung + perineal wound & 1 & 0 & 1 & 1 & \\
\hline $\begin{array}{l}\text { Lung + Bone + } \\
\text { Presacrum }\end{array}$ & 0 & 1 & 1 & 1 & \\
\hline Bone + Pelvic side wall & 1 & 0 & 1 & 1 & \\
\hline Liver + Presacrum & 0 & 0 & 0 & 1 & \\
\hline Liver + Pelvic side wall & 1 & 0 & 1 & 1 & \\
\hline \multicolumn{6}{|l|}{ Total: n (\%) } \\
\hline $\begin{array}{l}\text { Locoregional } \\
\text { recurrence }\end{array}$ & 4 & 2 & $6(7.9 \%)$ & $7(15.2 \%)$ & $\mathrm{P}=0.2467$ \\
\hline Distant metastasis & 6 & 5 & $11(14.5 \%)$ & $9(19.6 \%)$ & $\mathrm{P}=0.6182$ \\
\hline
\end{tabular}

present retrospective study may be a reasonable surrogate for the final oncologic results of the other ongoing further studies.

It needs to be mentioned that the criteria for pathologic staging of rectal cancer after CCRT, in which tumor regression grade (TRG) is used (Table 2), is quite different from that for rectal cancer without CCRT, in which the traditional TNM (tumor-node-metastasis) staging system is used. In this study, we frequently observed a rectal cancer after CCRT was with a high TRG (residual tumor amount less than 10\%) but remained a T3 stage in traditional TNM staging system, just because the scanty residual cancer cells were still accumulated in the subserosa layer of the recta wall, as was shown in the 4 cases of positive circumferential resection margin.

The mechanisms for the promising enhancement of the pathologic complete response by bevacizumab have been addressed by some authors [18-19], but are yet unproven. Willet et al. stressed the importance of bevacizumab in the normalization of tumor vasculature, which subsequently reversed the compromised delivery of oxygen and chemotherapeutic agents to the tumor bed and therefore induced better radio-chemotherapeutic sensitivity of the rectal cancer, as it was indirectly 


\section{A}

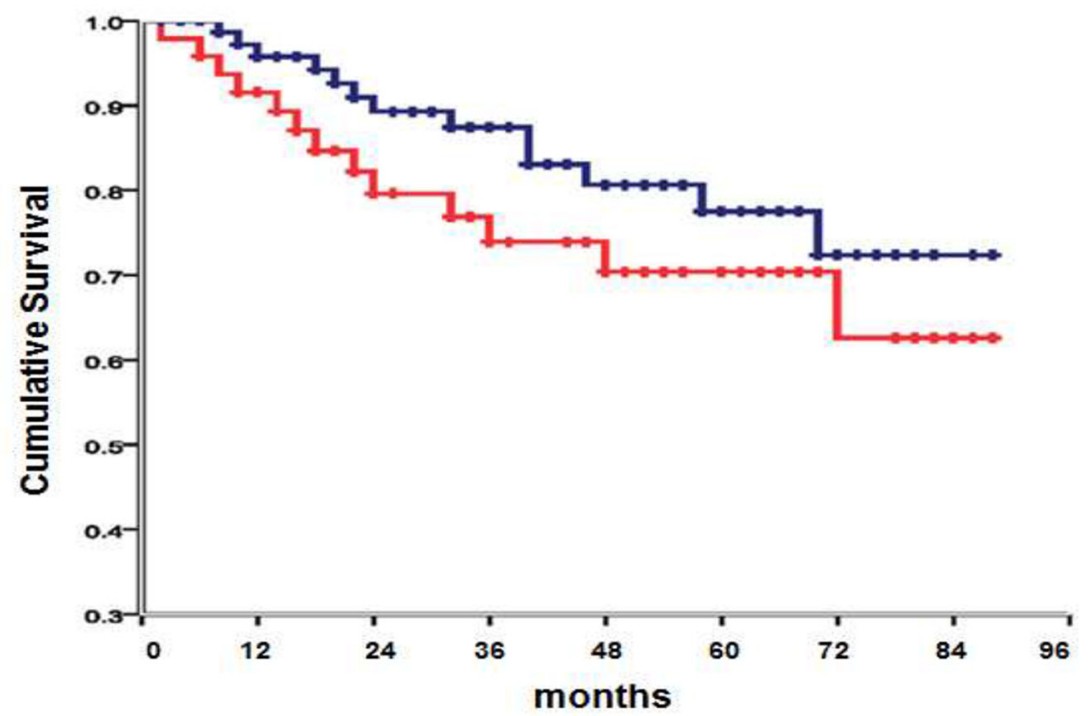

No. at risk

Cetuximab+FOLFOX

$\begin{array}{lll}-48 & 44\end{array}$

39

$37 \quad 36$

$36 \quad 35$

35

Bevacizumab+FOLFOX

73

69

$68 \quad 66$

65

63

63

35

63
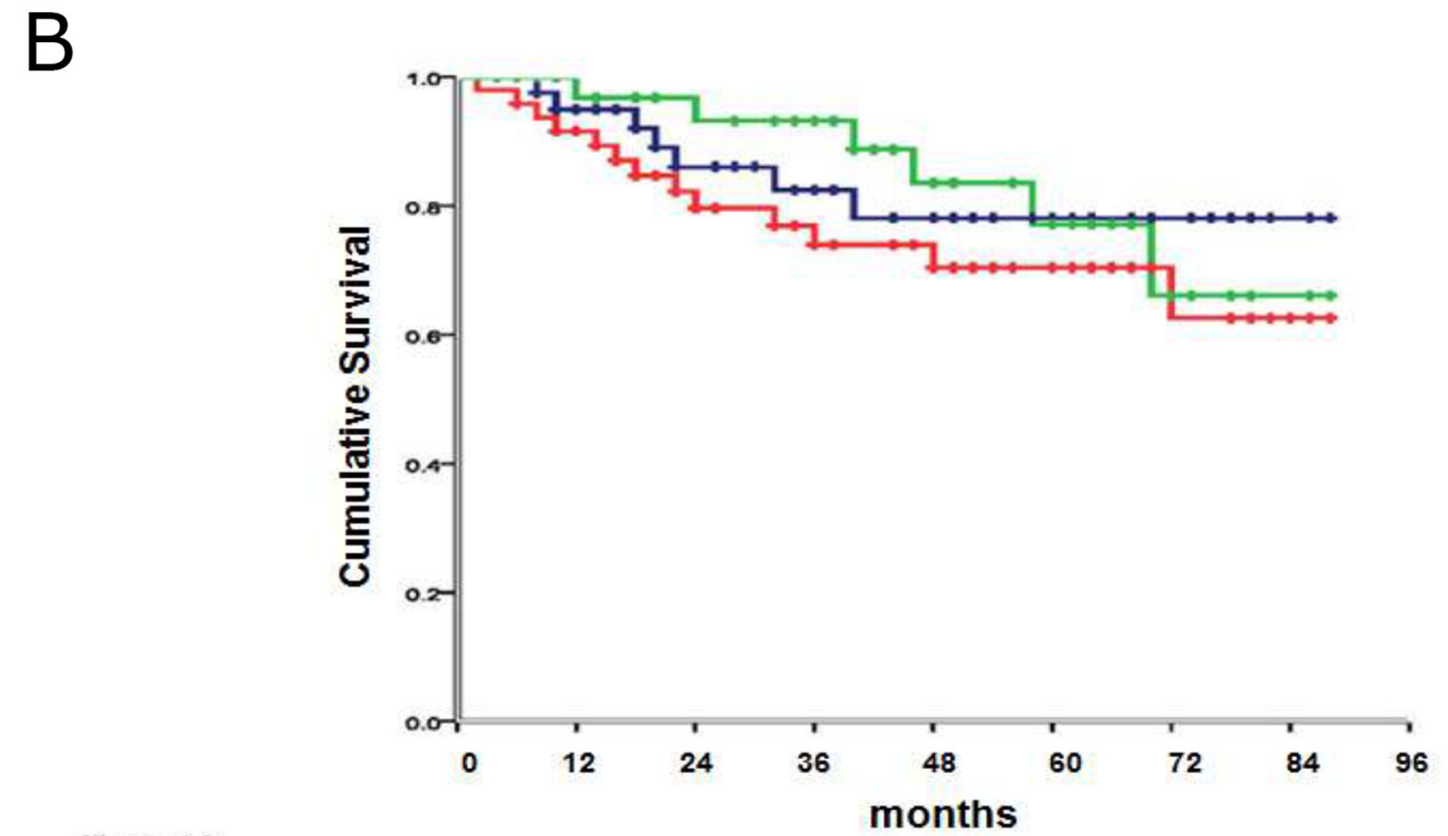

No. at risk

$\begin{array}{llllllllll}\text { Cetuximab+FOLFOX } & 48 & 44 & 39 & 37 & 36 & 36 & 35 & 35 & 35 \\ \begin{array}{l}\text { Bevacizumab+FOLFOX } \\ \text { with mutant k-ras }\end{array} & 40 & 38 & 35 & 34 & 33 & 33 & 33 & 33 \\ \begin{array}{l}\text { Bevacizumab+FOLFOX } \\ \text { with wild-type k-ras }\end{array} & 36 & 35 & 34 & 34 & 33 & 32 & 30 & 30 & 30\end{array}$

Figure 2: (A) Disease-free survival of patients receiving either bevacizumab or cetuximab in the CCRT treatment protocol. (B) Subset survival analysis regarding the influence of k-ras status on disease-free survival in bevacizumab- treated patients, in comparison with cetuximab- treated patients. 
Table 7: Treatment plan and the regimen for radiotherapy and chemotherapy

1. Patients with $\mathrm{T}_{3} \mathrm{~N}_{0-2}$ rectal cancer were prospectively recruited and stratified according to K-ras status and chemotherapeutic regimens (FOLFOX + bevacizumab vs. FOLFOX + cetuximab).

2. Pre-CCRT staging of cancer and CRM (circumferential resection margin) estimation were made based on the selective use of Transrectal Ultrasonography (TRUS), MRI (magnetic resonance imaging), multislice spiral CT and/or PET (positron emission tomography)-scan.

3. Radiotherapy (4500 cGy during 5 weeks/25 fractions) starts 2 weeks after the initial diagnosis and the radiotherapy is performed synchronously within the time course of 6-cycle chemotherapy.

4. Chemotherapy FOLFOX (5-FU: $2600 \mathrm{mg} / \mathrm{m}^{2}$; leucovorin: $300 \mathrm{mg} / \mathrm{m}^{2}$; maximum $500 \mathrm{mg}$; oxaliplatin: $85 \mathrm{mg} / \mathrm{m}^{2}$ ) + bevacizumab $(5 \mathrm{mg} / \mathrm{kg})$ or cetuximab $\left(450 \mathrm{mg} / \mathrm{m}^{2}\right)$, biweekly, 6 cycles, starts immediately after the initial diagnosis.

5. Laparoscopic total mesorectal excision (TME) was done 6 weeks after the final dose of chemotherapy.

evidenced by the increased plasma level of mediators such as soluble vascular endothelial growth factor receptor (sVEGFR1), vascular endothelial growth factor (VEGF), placental-derived growth factor (PIGF), interleukin 6 (IL-6) during treatment, and circulation endothelial cells (CECs) after treatment [28]. A few researchers argument against the oncologic benefits of preoperative CCRT for rectal cancer by showing that better local control of the tumor was not equal to longer overall survival of patients [29, 30]. However, based on the present study, we encourage the inclusion of bevacizumab in the preoperative CCRT treatment protocol because we believe that a higher rate of pathologic complete response can translate into a better local control of the primary cancer, which can therefore minimize the local recurrence rate and thus helping patients obviate the local recurrence-related sufferings such as intractable pelvic pain, genitourinary, and anorectal dysfunction.
It has been reported that liver steatosis was associated with the use of 5-fluorouracil and oxaliplatin through the mechanisms such as dysregulation in the production of lipoprotein and glycogen storage in the liver, and disruption of mitochondria, leading to increased oxidation of cellular proteins [31]; whereas sinusoidal dilatation of the liver has been considered to be uniquely caused by oxaliplatin, which can directly injure the endothelial cells lining the sinusoids of the liver [27-28, 30-32]. Remarkably, in the present study, we found that the FOLFOX plus bevacizumab-treated patients had a lower severity of sinusoidal injury; whereas cetuximab seemed to aggravate the liver toxicity. Although some previous authors suggested that bevacizumab may protect against sinusoidal damage, the underlying biochemical mechanisms remain unclear and further mechanistic studies are still needed [33-34]. On the other hand, we think that the liver toxicity may be aggravated by the
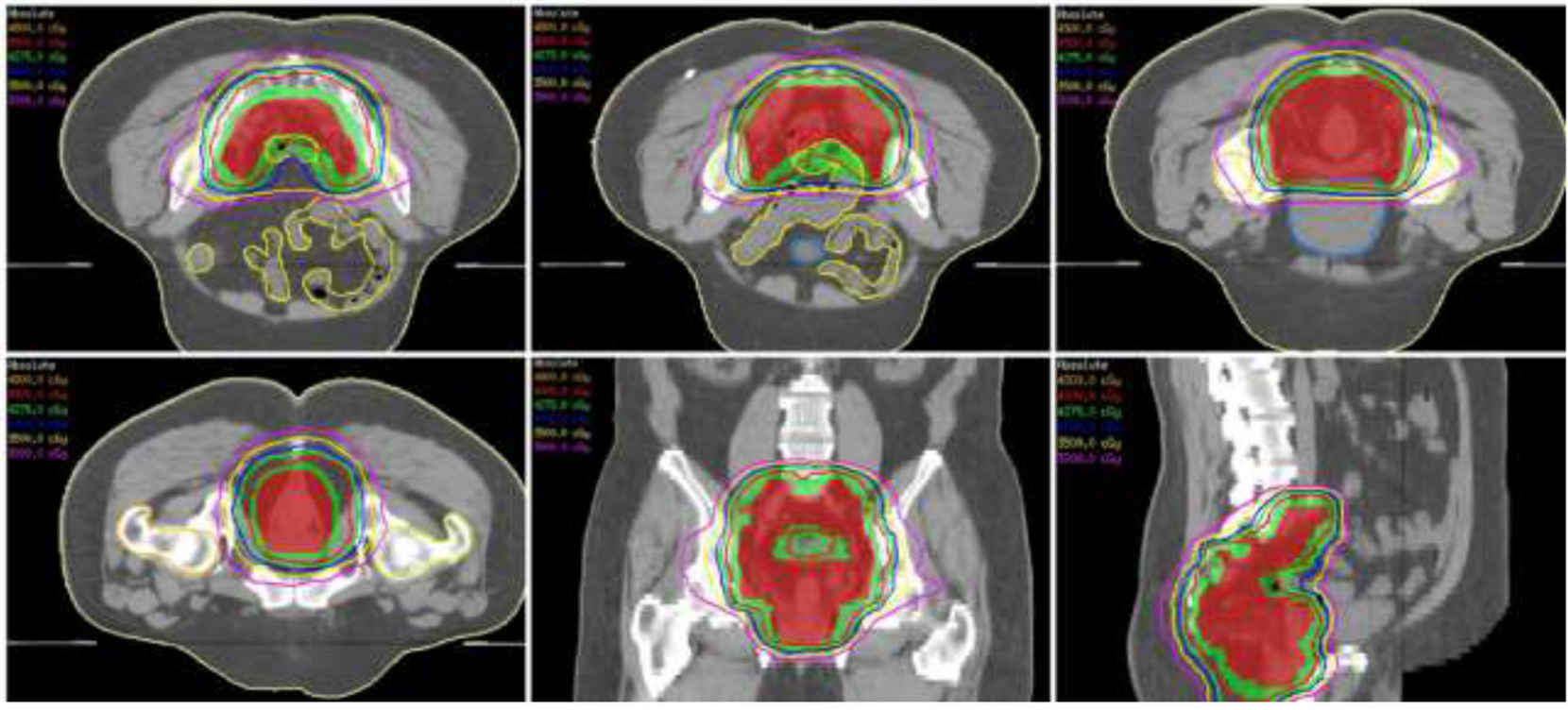

Figure 3: The isodose distributions for one representative patient planned by volumetric modulated arc therapy are shown with axial (upper panel and lower-left), coronal (lower-middle) and sagittal (lower-right) views. The red and green colorwash contours represent the clinical and planning target volumes, respectively. 
effects of antibody-dependent cytotoxicity (ADCC) inherent in the pharmacodynamics of cetuximab. Seeing the acneiform skin reaction and the tendency to develop lymphocyte infiltration in tumor histology in the present case series, we thus speculated that such a systemic inflammatory response aroused by cetuximab may potentiate FOLFOX in causing more severe liver toxicity. However, unlike the condition involving liver resection for the treatment of metastatic colorectal cancer [35], the morphologic liver toxicities associated with preoperative CCRT did not significantly increase the perioperative morbidities for the surgical resection of rectal cancer in the present case series. Usually, patients with severe morphologic liver toxicity induced by the aggressive preoperative CCRT using targeted agents retained a normal liver function. Even in the patients with an abnormal liver function $(36.8 \%, n=21)$, the alanine aminotransferase (ALT) was only moderately elevated and in most of such patients, abnormality of liver function was self-limited and recovered within three months after surgery. However, two cetuximab-treated patients were progressive to hepatic failure and surgical mortality.
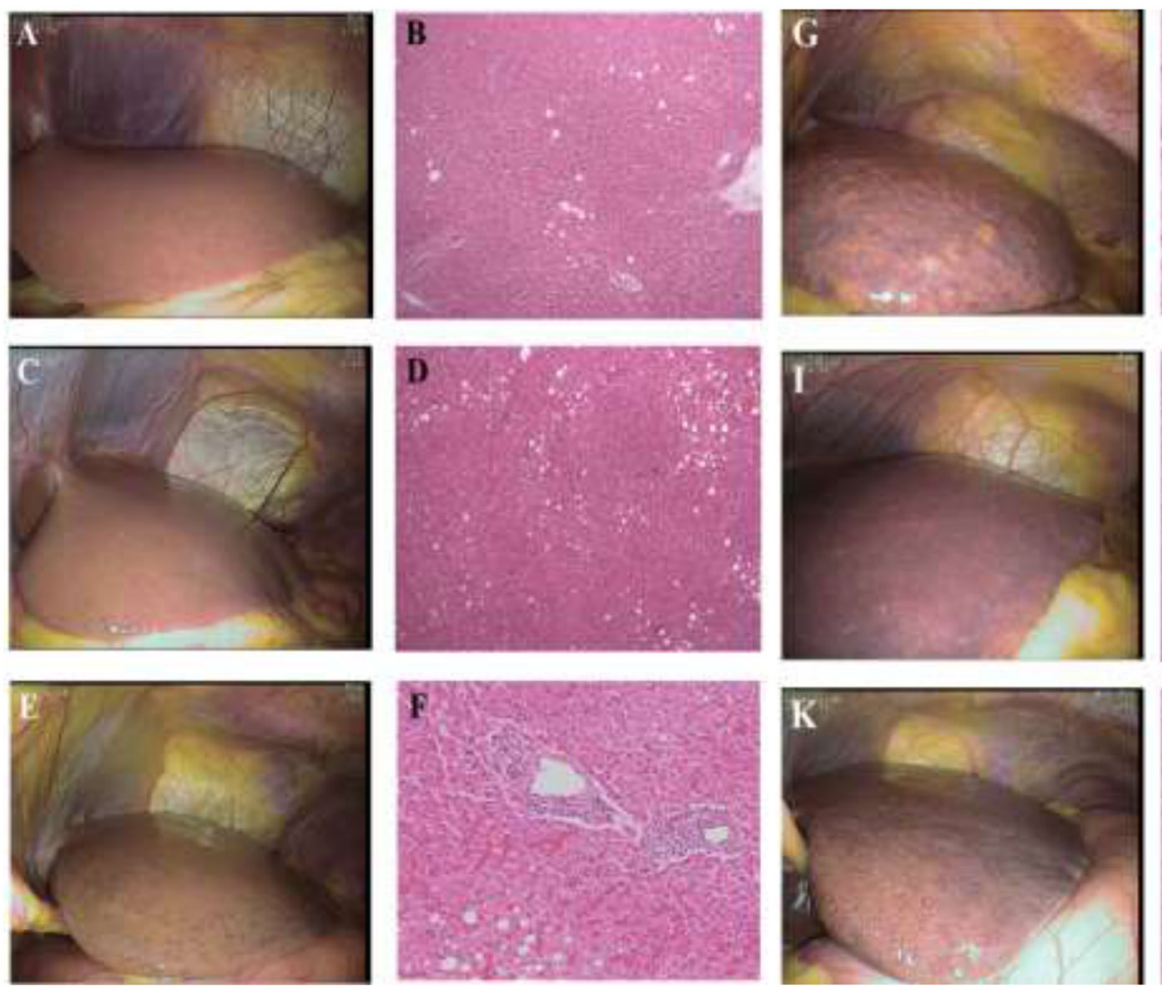
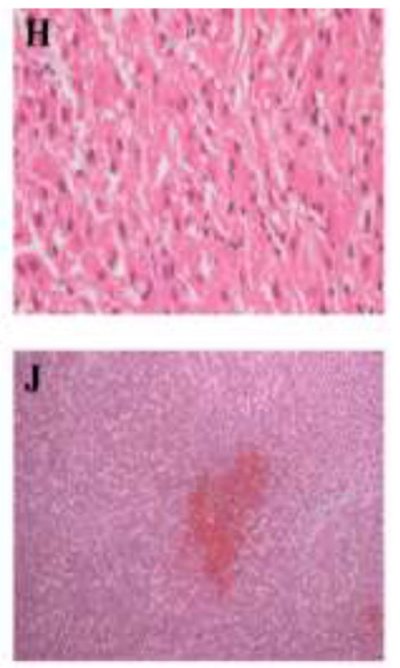
compared sur higher pathologic complete response rate for patients with $\mathrm{T}_{3} \mathrm{~N}_{0-2}$-staged advanced low rectal cancer requiring preoperative CCRT. Despite pre-operative chemotherapy with FOLFOX/XELOX with or without cetuximab (EXPERT-C trial) [36] has been used to treat locally advanced rectal carcinoma, concomitant to radiation or before chemoradiation, the use of monoclonal antibodies (bevacizumab or cetuximab) is still considered an investigational strategy. Data from the large randomized trial evaluating the role of neoadjuvant chemotherapy without radiation is pending (PROSPECT trial) [37]. What's more, Gasparini et al. reviewed the Phase II studies on fluoropyrimidines and bevacizumab+ RT, and showed that there had been no evidence that oxaliplatin had added significant higher pathologic complete response rate for locally advanced rectal cancer [38]. Therefore, The present retrospective study should mandate further multi-centered randomized prospective clinical trials to establish the oncologic efficacy of bevacizumab in the daily practice of preoperative CCRT for low rectal cancer.
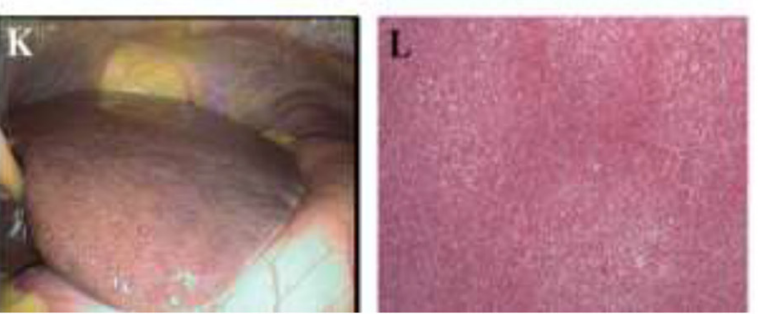

Figure 4: (A, B) A case of normal control of the liver toxicity. The steatosis is less than 3\% of the histologic view. (C, D) A case of mild steatosis without sinusoidal dilatation. The steatosis is less than $33 \%$ of the histologic view. (E, F) A case of moderate sinusoidal dilatation (33-66\%) in the laparoscopic and the histologic view. (G, H) A case of severe liver injury with marked sinusoidal dilatation in laparoscopic view and microvesicular steatosis in histology. (I, J) A case of severe sinusoidal dilatation (laparoscopic view) with centrilobular necrosis (histologic view). (K, L) A case of severe liver injury with moderate steatosis and severe sinusoidal congestion. 


\section{MATERIALS AND METHODS}

\section{Patient recruitment and stratification}

Prospectively enrolled clinicopathologic data of consecutive patients with clinically $\mathrm{T}_{3} \mathrm{~N}_{0-2} \mathrm{M}_{0}$-staged distal rectal cancer and treated between March 2008 and August 2011 at the Colorectal Division, Department of Surgery, National Taiwan University Hospital, were retrospectively reviewed. This study has obtained approval from National Taiwan University Hospital (NTUH) Research Ethics Committee (REC) and was designated as: 201103126MB. Distal rectal cancer was defined as a tumor located within $10 \mathrm{~cm}$ above the anal verge. The pretreatment clinical stage of the tumor was determined by the selective use of transrectal ultrasonography (TRUS), magnetic resonance imaging (MRI), multi-slice spiral computed tomography (CT), and/or positron-emission tomography (PET). Patients with abnormal liver function or severe liver steatosis, as screened by preoperative blood sampling and ultrasonography, were excluded. The K-ras status of the cancer was determined by pretreatment colonoscopic tumor biopsy. The codon 12 and 13 of the K-ras gene were screened by a direct sequencing of the polymerase-chainreaction-enriched products, as reported before [14, 21].

In regard of the indication for treatment arm, the choice of cetuximab or bevacizumab is firstly according to the mutation status of K-ras gene. If K-ras gene is mutant, the patient can only choose the FOLFOX + bevacizumab regimen in CCRT protocol. However, if the K-ras gene is wild-type, generally, the choice of FOLFOX + bavacizumab or FOLFOX + cetuximab is up to the patients' preference. In such condition, the patients with poor economic status usually chose FOLFOX + bevacizumab because it was cheaper.

The patients were stratified into 3 groups: bevacizumab +FOLFOX-treated and with wild-type k-ras status, bevacizumab+FOLFOX-treated and with mutant k-ras status, and cetuximab+FOLFOX-treated and with wild-type k-ras status. Ample studies regarding head-to-head comparison between bevacizumab and cetuximab have shown that cetuximab is superior to bevacizumab in metastatic colorectal cancer with wild-type K-ras gene. And, some reports showed that the mutational status of K-ras gene is associated with patients' prognosis. Therefore, the subset analysis is done to clarify the influence of K-ras gene per se on the patient survival.

The primary endpoints of the present study were the rate of the pathologic complete response and safety profiles, especially the chemotherapy-induced liver toxicities. We first compared the clinicopathologic features between cetuximab+FOLFOX and bevacizumab+FOLFOX treated patients, and then a subset analysis was made within bevacizumab+FOLFOX treated patients to investigate the influence of K-ras status on the treatment outcomes.

\section{Treatment}

The eligible patients were subjected to the preoperative CCRT regimen, which is shown in Table 7 and Figure 3. Briefly, immediately after the completion of clinical staging, the patients received the first course of chemotherapy, which was followed by long-course radiation. Generally, the interval between the first course of chemotherapy and the initiation of radiation is one week. The patients underwent 6 cycles of chemotherapy at 2-week intervals. The $4500 \mathrm{cGy}$ radiotherapy, 25 fractions in 5 consecutive weeks, was given synchronously in-between the time course of chemotherapy. The CCRT treatment protocol was completed at 14 weeks after the initial diagnosis and re-staging of patients was performed at this time point. Thereafter, a standardized laparoscopic total mesorectal excision (TME), as described in our previous publications [22], was scheduled for the patients, generally 6 weeks after the final dose of chemotherapy (bevacizumab or cetuximab plus FOLFOX).

\section{Histopathologic scrutiny of the resected tumor specimen after CCRT}

The preparation of tissue specimens for the assessment of tumor response to CCRT and the quality of TME were performed with reference to guidelines from Nagtegaal et al. [23] and the contemporary literature review [24].

The circumferential resection margin (CRM) was considered to be tumor-free when the safety margin was more than $2 \mathrm{~mm}$. The pathological response of rectal cancer to CCRT was graded from 0-5 (Table 2) according to the criteria modified from Dworak et al. [25-26].

\section{Evaluation of liver toxicity to CCRT}

The liver toxicity was graded by the intra-operative laparoscopic view of the liver surface. We classified the morphologic liver injury as severe: when both sinusoidal dilatation and steatosis represented more than one-third of the laparoscopic view of the liver surface; moderate: when sinusoidal dilatation occupied more than one-third but steatosis was noted for less than one-third of the liver surface, or vice versa; mild: when both steatosis dilatation and steatosis accounted for less than onethird of the liver surface. We validated the laparoscopic grading of liver toxicity based on our pilot study which showed the close correlation between laparoscopic view and histopathology (Supplementary Videos 1-7), in which presence of sinusoidal dilatation (SD) was recorded using the Rubbia-Brandt Score [27] as follows: 0, absent; 1, mild (centrilobular involvement limited to one-third of the lobular surface); 2, moderate (centrilobular involvement extending to two-thirds of the lobular surface); 3 , severe (complete lobular involvement), and the liver steatosis was graded from 0 to 3 : absent $5 \%$ (grade 0 ), $5 \% \sim 33 \%$ of 
hepatocytes (grade 1), between $33 \%$ and $66 \%$ (grade 2), and $>66 \%$ (grade 3 ) (Figure 4, A F).

\section{Assessment of safety profiles}

The adverse effects of CCRT and surgical complications of both treatment groups were well recorded in the case report forms, focusing on the bevacizumab and cetuximab-related side effects and any severe adverse events that caused the discontinuation of treatment.

\section{Statistics}

All patients were prospectively followed up from the initial diagnosis of cancer until November, 2016. Data were assessed according to the intention-to-treat principle. Patients who died without a reported tumor recurrence were assumed to have had a recurrence at death unless it was clearly demonstrated otherwise, in which case the patients' data were censored on the date of death in the analysis of the time-to-recurrence. Kaplan-Meier curves were constructed to estimate the distribution of the disease-free survival. The primary analysis consisted of a two-sided log-rank test comparing time with recurrence among patient groups. In evaluating secondary endpoints, two tailed Fisher's exact test or Chi-square test with or without Yates' correction was appropriately used to analyze the categorical data, whereas continuous data were compared by Student's $t$-test. The significance level of all tests was set at $p<0.05$.

\section{Author contributions}

Jin-Tung Liang was responsible for the study design, implementation and writing the manuscript.

Tzu-Chun Chen and John Huang were responsible for the implementation and evaluation of treatment outcomes for patients.

Yung-Ming Jeng was responsible for the evaluation surgical pathology

Jason Chia-Hsien Cheng was in charge of the accrual and radiation therapy for patients.

\section{CONFLICTS OF INTEREST}

The authors Jin-Tung Liang ${ }^{1}, \mathrm{MD}, \mathrm{PhD}$, Tzu-Chun Chen, M.D. ${ }^{1,}$ John Huang ${ }^{1}, \mathrm{MD}, \mathrm{PhD}$, Yung-Ming Jeng ${ }^{2}$, $\mathrm{MD}, \mathrm{PhD}$, Jason Chia-Hsien Cheng ${ }^{3}$, MD, PhD.

The authors declare no conflicts of interest during the whole process of study design and the publication of this manuscript.

\section{FUNDING}

The present study received grant support (MOHW106-TDU-B-211-144005) from Ministry of Health, Taiwan, ROC.

\section{REFERENCES}

1. Nelson H, Petrelli N, Carlin A, Couture J, Fleshman J, Guillem J, Miedema B, Ota D, Sargent D. Guidelines 2000 for colon and rectal cancer surgery. J Natl Cancer Inst. 2001; 93: 583-96.

2. O'Neil BH, Tepper JE. Current options for the management of rectal cancer. Curr Treat Options Oncol. 2007; 8: 331-38.

3. Quah HM, Chou JF, Gonen M, Shia J, Schrag D, Saltz LB, Goodman KA, Minsky BD, Wong WD, Weiser MR. Pathologic stage is most prognostic of disease-free survival in locally advanced rectal cancer patients after preoperative chemoradiation. Cancer. 2008; 113: 57-64.

4. Rödel C, Martus P, Papadoupolos T, Füzesi L, Klimpfinger M, Fietkau R, Liersch T, Hohenberger W, Raab R, Sauer R, Wittekind C. Prognostic significance of tumor regression after preoperative chemoradiotherapy for rectal cancer. J Clin Oncol. 2005; 23: 8688-696.

5. García-Aguilar J, Hernandez de Anda E, Sirivongs P, Lee $\mathrm{SH}$, Madoff RD, Rothenberger DA. A pathologic complete response to preoperative chemoradiation is associated with lower local recurrence and improved survival in rectal cancer patients treated by mesorectal excision. Dis Colon Rectum. 2003; 46: 298-304.

6. Theodoropoulos G, Wise WE, Padmanabhan A, Kerner BA, Taylor CW, Aguilar PS, Khanduja KS. T-level downstaging and complete pathologic response after preoperative chemoradiation for advanced rectal cancer result in decreased recurrence and improved disease-free survival. Dis Colon Rectum. 2002; 45: 895-903.

7. André T, Boni C, Mounedji-Boudiaf L, Navarro M, Tabernero J, Hickish T, Topham C, Zaninelli M, Clingan P, Bridgewater J, Tabah-Fisch I, de Gramont A. Oxaliplatin, fluorouracil, and leucovorin as adjuvant treatment for colon cancer. N Engl J Med. 2004; 3: 2343-51.

8. Rödel C, Liersch T, Hermann RM, Arnold D, Reese T, Hipp M, Fürst A, Schwella N, Bieker M, Hellmich G, Ewald H, Haier J, Lordick F, et al. Multicenter phase II trial of chemoradiation with oxaliplatin for rectal cancer. J Clin Oncol. 2007; 25: 110-17.

9. Ryan DP, Niedzwiecki D, Hollis D, Mediema BE, Wadler S, Tepper JE, Goldberg RM, Mayer RJ; Cancer and Leukemia Group B 89901. Phase I/II study of preoperative oxaliplatin, fluorouracil, and external-beam radiation therapy in patients with locally advanced rectal cancer: Cancer and Leukemia Group B 89901. J Clin Oncol. 2006; 24: 2557-62.

10. Chau I, Brown G, Cunningham D, Tait D, Wotherspoon A, Norman AR, Tebbutt N, Hill M, Ross PJ, Massey A, Oates J. Neoadjuvant capecitabine and oxaliplatin followed by synchronous chemoradiation and total mesorectal excision in magnetic resonance imaging-defined poor-risk rectal cancer. J Clin Oncol. 2006; 24: 668-74. 
11. Calvo FA, Serrano FJ, Diaz-González JA, Gomez-Espi M, Lozano E, Garcia R, de la Mata D, Arranz JA, GarcíaAlfonso P, Pérez-Manga G, Alvarez E. Improved incidence of pT0 downstaged surgical specimens in locally advanced rectal cancer (LARC) treated with induction oxaliplatin plus 5-fluorouracil and preoperative chemoradiation. Ann Oncol. 2006; 17: 1103-10.

12. Gruenberger B, Tamandl D, Schueller J, Scheithauer W, Zielinski C, Herbst F, Gruenberger T. Bevacizumab, capecitabine, and oxaliplatin as neoadjuvant therapy for patients with potentially curable metastatic colorectal cancer. J Clin Oncol. 2008; 26: 1830-35.

13. Adam R, Aloia T, Lévi F, Wicherts DA, de Haas RJ, Paule B, Bralet MP, Bouchahda M, Machover D, Ducreux M, Castagne V, Azoulay D, Castaing D. Hepatic resection after rescue cetuximab treatment for colorectal liver metastases previously refractory to conventional systemic therapy. J Clin Oncol. 2007; 25: 4593-602.

14. Karapetis CS, Khambata-Ford S, Jonker DJ, O'Callaghan CJ, Tu D, Tebbutt NC, Simes RJ, Chalchal H, Shapiro JD, Robitaille S, Price TJ, Shepherd L, Au HJ, et al. K-ras mutations and benefit from cetuximab in advanced colorectal cancer. N Engl J Med. 2008; 359: 1757-65.

15. Machiels JP, Sempoux C, Scalliet P, Coche JC, Humblet Y, Van Cutsem E, Kerger J, Canon JL, Peeters M, Aydin S, Laurent S, Kartheuser A, Coster B, et al. Phase I/II study of preoperative cetuximab, capecitabine, and external beam radiotherapy in patients with rectal cancer. Ann Oncol. 2007; 18: 738-44.

16. Hofheinz RD, Horisberger K, Woernle C, Wenz F, KrausTiefenbacher U, Kähler G, Dinter D, Grobholz R, Heeger S, Post S, Hochhaus A, Willeke F. Phase I trial of cetuximab in combination with capecitabine, weekly irinotecan, and radiotherapy as neoadjuvant therapy for rectal cancer. Int J Radiat Oncol Biol Phys. 2006; 66: 1384-90.

17. Rödel C, Sauer R. Integration of novel agents into combined-modality treatment for rectal cancer patients. Strahlenther Onkol. 2007; 183: 227-35.

18. Willett CG, Boucher Y, di Tomaso E, Duda DG, Munn LL, Tong RT, Chung DC, Sahani DV, Kalva SP, Kozin SV, Mino M, Cohen KS, Scadden DT, et al. Direct evidence that the VEGF-specific antibody bevacizumab has antivascular effects in human rectal cancer. Nat Med. 2004; 10: 145-47.

19. Willett CG, Duda DG, di Tomaso E, Boucher Y, Czito BG, Vujaskovic Z, Vlahovic G, Bendell J, Cohen KS, Hurwitz HI, Bentley R, Lauwers GY, Poleski M, et al. Complete pathological response to bevacizumab and chemoradiation in advanced rectal cancer. Nat Clin Pract Oncol. 2007; 4: 316-21.

20. Hurwitz HI, Yi J, Ince W, Novotny WF, Rosen O. The clinical benefit of bevacizumab in metastatic colorectal cancer is independent of K-ras mutation status: analysis of a phase III study of bevacizumab with chemotherapy in previously untreated metastatic colorectal cancer. Oncologist. 2009; 14: 22-8.
21. Linardou H, Dahabreh IJ, Kanaloupiti D, Siannis F, Bafaloukos D, Kosmidis P, Papadimitriou CA, Murray S. Assessment of somatic k-RAS mutations as a mechanism associated with resistance to EGFR-targeted agents: a systematic review and meta-analysis of studies in advanced non-small-cell lung cancer and metastatic colorectal cancer. Lancet Oncol. 2008; 9: 962-72.

22. Liang JT, Lai HS, Cheng KW. Technical feasibility of laparoscopic total mesorectal excision for patients with low rectal cancer after concurrent radiation and chemotherapy with bevacizumab plus FOLFOX. Surg Endosc. 2011; 25: 305-8.

23. Nagtegaal ID, Marijnen CA, Kranenbarg EK, van de Velde CJ, van Krieken JH, Pathology Review Committee, Cooperative Clinical Investigators. Circumferential margin involvement is still an important predictor of local recurrence in rectal carcinoma: not one millimeter but two millimeters is the limit. Am J Surg Pathol. 2002; 26: 350-57.

24. Parfitt JR, Driman DK. The total mesorectal excision specimen for rectal cancer: a review of its pathological assessment. J Clin Pathol. 2007; 60: 849-55.

25. Dworak O, Keilholz L, Hoffmann A. Pathological features of rectal cancer after preoperative radiochemotherapy. Int J Colorectal Dis. 1997; 12: 19-23.

26. Shia J, Guillem JG, Moore HG, Tickoo SK, Qin J, Ruo L, Suriawinata A, Paty PB, Minsky BD, Weiser MR, Temple LK, Wong WD, Klimstra DS. Patterns of morphologic alteration in residual rectal carcinoma following preoperative chemoradiation and their association with long-term outcome. Am J Surg Pathol. 2004; 28: 215-23.

27. Rubbia-Brandt L, Audard V, Sartoretti P, Roth AD, Brezault C, Le Charpentier M, Dousset B, Morel P, Soubrane O, Chaussade S, Mentha G, Terris B. Severe hepatic sinusoidal obstruction associated with oxaliplatin-based chemotherapy in patients with metastatic colorectal cancer. Ann Oncol. 2004; 15: 460-6.

28. Willett CG, Duda DG, di Tomaso E, Boucher Y, Ancukiewicz M, Sahani DV, Lahdenranta J, Chung DC, Fischman AJ, Lauwers GY, Shellito P, Czito BG, Wong TZ, et al. Efficacy, safety, and biomarkers of neoadjuvant bevacizumab, radiation therapy, and fluorouracil in rectal cancer: a multidisciplinary phase II study. J Clin Oncol. 2009; 27: 3020-6.

29. Liang JT, Cheng YM, Chang KJ, Chien CT, Hsu HC. Reappraisal of K-ras and p53 gene mutations in the recurrence of Dukes' B2 rectal cancer after curative resection. Hepato-Gastroenterology. 1999; 46: 830-7.

30. Peeters KC, Marijnen CA, Nagtegaal ID, Kranenbarg EK, Putter H, Wiggers T, Rutten H, Pahlman L, Glimelius B, Leer JW, van de Velde CJ; Dutch Colorectal Cancer Group. The TME trial after a median follow-up of 6 years: increased local control but no survival benefit in irradiated patients with resectable rectal carcinoma. Ann Surg. 2007; 246: 693-701. 
31. Hübscher SG. Histological assessment of non-alcoholic fatty liver disease. Histopathology. 2006; 49: 450-65.

32. Cleary JM, Tanabe KT, Lauwers GY, Zhu AX. Hepatic toxicities associated with the use of preoperative systemic therapy in patients with metastatic colorectal adenocarcinoma to the liver. Oncologist. 2009; 14: 1095-105.

33. Ribero D, Wang H, Donadon M, Zorzi D, Thomas MB, Eng C, Chang DZ, Curley SA, Abdalla EK, Ellis LM, Vauthey JN. Bevacizumab improves pathologic response and protects against hepatic injury in patients treated with oxaliplatin-based chemotherapy for colorectal liver metastases. Cancer. 2007; 110: 2761-7.

34. Klinger M, Eipeldauer S, Hacker S, Herberger B, Tamandl D, Dorfmeister M, Koelblinger C, Gruenberger B, Gruenberger T. Bevacizumab protects against sinusoidal obstruction syndrome and does not increase response rate in neoadjuvant XELOX/FOLFOX therapy of colorectal cancer liver metastases. Eur J Surg Oncol. 2009; 35: 515-20.

35. Aloia T, Sebagh M, Plasse M, Karam V, Lévi F, Giacchetti S, Azoulay D, Bismuth H, Castaing D, Adam R. Liver histology and surgical outcomes after preoperative chemotherapy with fluorouracil plus oxaliplatin in colorectal cancer liver metastases. J Clin Oncol. 2006; 24 : 4983-90.

36. Dewdney A, Cunningham D, Tabernero J, Capdevila J, Glimelius B, Cervantes A, Tait D, Brown G, Wotherspoon A, Gonzalez de Castro D, Chua YJ, Wong R, Barbachano $\mathrm{Y}$, et al. Multicenter randomized phase II clinical trial comparing neoadjuvant oxaliplatin, capecitabine, and preoperative radiotherapy with or without cetuximab followed by total mesorectal excision in patients with highrisk rectal cancer (EXPERT-C). J Clin Oncol. 2012; 30: 1620-7.

37. Weiser MR, Fichera A, Schrag D, Boughey JC, You YN. Progress in the PROSPECT trial: precision treatment for rectal cancer? Bull Am Coll Surg. 2015; 100: 51-2.

38. Torino F, Sarmiento R, Gasparini G. The contribution of targeted therapy to the neoadjuvant chemoradiation of rectal cancer. Crit Rev Oncol Hematol. 2013; 87: 283-305. 